\title{
Advances in computational intelligence
}

\section{Selected and improved papers of the 14th international work-conference on artificial neural networks (IWANN 2017)}

\author{
Miguel Atencia ${ }^{1} \cdot$ Gonzalo Joya $^{1} \cdot$ Francisco García-Lagos ${ }^{1}$
}

Received: 4 June 2019/Accepted: 20 June 2019/Published online: 26 June 2019

(c) Springer-Verlag London Ltd., part of Springer Nature 2019

The 14th edition of the biennial International Work-Conference on Artificial Neural Networks (IWANN 2017) gathered together more than one hundred significant contributors in the fields of artificial neural networks, machine learning, computational intelligence, and related topics. After the conference, which was held in Cádiz (Spain), in June 2017, a set of outstanding papers were selected and their authors invited to prepare an extended version. This special issue of Neural Computing and Applications comprises the nine papers that were finally accepted after a thorough reviewing process.

The IWANN events were born in 1991, and are currently co-chaired by researchers from the Universidad de Málaga, the Universidad de Granada, and the Universitat Politècnica de Catalunya. Since its inception, all the papers accepted to the conferences have been collected in volumes published by Springer Verlag in the book series Lecture Notes in Computer Science [3-5, 7, 11-20, 24, 26-30, 33]. Besides, a number of special issues of top-tier journals have comprised selected papers from the latest editions, which were revised and substantially extended. These special issues were published in Neurocomputing [2, 6, 21, 22, 31, 32], Neural Processing Letters [1, 8, 23], and Soft Computing [25].

Despite the difficult delimitation of the field, the basic ideas of Neural Computation [10] have always somehow been present in all the advances: parallelism and learning. The range of applications has also been more and more

Miguel Atencia

matencia@ctima.uma.es

Gonzalo Joya

gjoya@uma.es

Francisco García-Lagos

fgl@uma.es

1 Universidad de Málaga, Málaga, Spain enlarged, so nowadays machine learning is pervasive, not only in scientific or engineering disciplines, but also in all aspects of society. Undeniably, the major breakthrough in the last decade is the success of Deep Learning [9] algorithms. Yet the application of computational intelligence techniques to critical tasks requires a continued research effort to provide both rigorous support and explanation to decision making.

Some of the papers selected for this special issue focus on principled applications of machine learning to diverse important real-world tasks, including engineering, medical diagnostics, image processing, and bioinformatics. Other contributions use such applications as a proof of concept to design, analyse, and test new architectures or parametersetting methodologies. Therefore, the interaction between theoretical advances and applied results leads to a synergy that is consistent with the aims and scope of Neural Computing and Applications. The nine accepted papers can be roughly classified into three categories:

- Biological applications Three contributions place themselves at the frontier of computational intelligence and biomedical disciplines.

- The paper Analysis on the potential of an EAsurrogate modelling tandem for deep learning parametrization: an example for cancer classification from medical images by Ruxandra Stoean, introduces a novel methodology to efficiently set the parameters of a convolutional neural network and rank the importance of the involved variables, in the context of medical image interpretation.

- The authors Francisco J. Veredas, Daniel Urda, José L. Subirats, Francisco R. Cantón, and Juan C. Aledo study the selection of biological markers that forecast the occurrence of certain chemical events in proteins, in their paper Combining feature 
engineering and feature selection to improve the prediction of methionine oxidation sites in proteins.

- The different, but also biology-related, field of wearable devices used to monitor activity of mobility impaired or elderly is explored in the paper Posture transition analysis with barometers: contribution to accelerometer-based algorithms by Daniel Rodríguez-Martín, Albert Samà, Carlos Pérez-López, Andreu Català, and Joan Cabestany.

- Industrial engineering The remarkably important tasks related to a variety of technological processes are the object of five accepted papers.

- The paper Monte Carlo uncertainty analysis of an ANN-based spectral analysis method, by José Ramón Salinas, Francisco García-Lagos, Javier Diaz de Aguilar, Gonzalo Joya, and Francisco Sandoval, deals with a neural algorithm that computes signal spectra. The method is taken into a stochastic context, providing a measure of the uncertainty of its results.

- The field of fault diagnosis is explored by Andre Loechte, Ole Gebert, Daniel Heming, Klaus T. Kallis, and Peter Gloesekoetter, in their paper $A$ quadratic boundedness approach to a neural network-based simultaneous estimation of actuator and sensor faults. In particular, the contribution lies in the robust simultaneous estimation of uncertainty in both types of transducers.

- The contribution authored by L. Cornejo-Bueno, C. Camacho-Gómez, A. Aybar-Ruiz, L. Prieto, A. Barea-Ropero, and S. Salcedo-Sanz proposes a hybrid algorithm for the classification of lowprobability events in wind farms, under the title Wind Power Ramp Events Detection with a Hybrid Neuro-Evolutionary Approach.

- The paper An Intelligent Transportation System to Control Air Pollution and Road Traffic in Cities Integrating CEP and Colored Petri nets, by Gregorio Díaz, Hermenegilda Macià, Valentín Valero, Juan Boubeta-Puig, and Fernando Cuartero, tackles the critical issue of air quality in urban areas by building a city map model that allows for simulation and decision making.

- Image processing Finally, the paper Pooling spike neural network for fast rendering in global illumination, authored by Joseph Constantin, Andre Bigand, and Ibtissam Constantin, constitutes arguably its own category by proposing a neural algorithm to generate photo-realistic images.

The guest editors gratefully acknowledge the outstanding work of all the contributing authors, as well as the committed effort of the anonymous reviewers to provide useful comments and suggestions that have greatly improved the quality of the papers. We would also like to thank Dr. John MacIntyre and the Neural Computing and Applications editorial board for giving us the opportunity to publish this special issue, which could have hardly come into existence without the efficient management by the editorial staff of the publisher Springer.

We are glad to invite all authors and interested readers of this issue to contribute to future IWANN conferences, by proposing a Special Session and submitting a paper. Upcoming editions of IWANN are announced at the web page: http://iwann.uma.es.

Acknowledgements This work has been partially supported by the Ministerio de Economía, Industria y Competitividad (Spain) through the project TIN2017-88728-C2-1-R.

\section{References}

1. Arostegui JMM, Cabestany J, Rojas I (2013) Preface. Neural Process Lett 37(1):1-1. https://doi.org/10.1007/s11063-0129273-6

2. Atencia M, Sandoval F, Prieto A (2015) Advances in computational intelligence: selected and improved papers of the 12th international work-conference on artificial neural networks (IWANN 2013). Neurocomputing 164, 1-4 . https://doi.org/10. 1016/J.NEUCOM.2015.02.074.

3. Cabestany J, Prieto A, Sandoval F (2005) Computational intelligence and bioinspired systems, vol 3512. Lecture notes in computer science. Springer, Berlin. https://doi.org/10.1007/ b136983

4. Cabestany J, Rojas I, Joya G (2011) Advances in computational intelligence, vol 6692. Lecture notes in computer science. Springer, Berlin. https://doi.org/10.1007/978-3-642-21498-1

5. Cabestany J, Rojas I, Joya G (2011) Advances in computational intelligence, vol 6691. Lecture notes in computer science. Springer, Berlin. https://doi.org/10.1007/978-3-642-21501-8

6. Cabestany J, Sandoval F, Prieto A (2009) Computational and ambient intelligence. Neurocomputing 72(16-18):3539-3540

7. Cabestany J, Sandoval F, Prieto A, Corchado JM (2009) Bioinspired systems: computational and ambient intelligence, vol 5517. Lecture notes in computer science. Springer, Berlin. https:// doi.org/10.1007/978-3-642-02478-8

8. Catalá A, Joya G, Rojas I (2017) Editorial. Neural Process Lett 46(3):747-750. https://doi.org/10.1007/s11063-017-9743-y

9. Goodfellow I, Bengio Y, Courville A (2017) Deep learning. The MIT Press, Cambridge

10. Haykin SS, Haykin SS (2009) Neural networks and learning machines. Prentice Hall/Pearson, Englewood Cliffs

11. Mira J, Álvarez JR (2003) Artificial neural nets problem solving methods, vol 2687. Lecture notes in computer science. Springer, Berlin. https://doi.org/10.1007/3-540-44869-1

12. Mira J, Álvarez JR (2003) Computational methods in neural modeling, vol 2686. Lecture notes in computer science. Springer, Berlin. https://doi.org/10.1007/3-540-44868-3

13. Mira J, Cabestany J, Prieto A (1993) New trends in neural computation, vol 686. Lecture notes in computer science. Springer, Berlin. https://doi.org/10.1007/3-540-56798-4

14. Mira J, Moreno-Díaz R, Cabestany J (1997) Biological and artificial computation: from neuroscience to technology, vol 
1240. Lecture notes in computer science. Springer, Berlin. https:// doi.org/10.1007/BFb0032457

15. Mira J, Prieto A (2001) Bio-inspired applications of connectionism, vol 2085. Lecture notes in computer science. Springer, Berlin. https://doi.org/10.1007/3-540-45723-2

16. Mira J, Prieto A (2001) Connectionist models of neurons, learning processes, and artificial intelligence, vol 2084. Lecture notes in computer science. Springer, Berlin. https://doi.org/10. 1007/3-540-45720-8

17. Mira J, Sánchez-Andrés JV (1999) Engineering applications of bio-inspired artificial neural networks, vol 1607. Lecture notes in computer science. Springer, Berlin. https://doi.org/10.1007/ $\mathrm{BFb} 0100465$

18. Mira J, Sánchez-Andrés JV (1999) Foundations and tools for neural modeling, vol 1606. Lecture notes in computer science. Springer, Berlin. https://doi.org/10.1007/BFb0098154

19. Mira J, Sandoval F (1995) From natural to artificial neural computation, vol 930. Lecture notes in computer science. Springer, Berlin. https://doi.org/10.1007/3-540-59497-3

20. Prieto A (1991) Artificial neural networks, vol 540. Lecture notes in computer science. Springer, Berlin. https://doi.org/10.1007/ $\mathrm{BFb} 0035870$

21. Prieto A, Atencia M, Sandoval F (2013) Advances in artificial neural networks and machine learning. Neurocomputing 121:1-4. https://doi.org/10.1016/j.neucom.2013.01.008

22. Prieto A, Cabestany J, Sandoval F (2007) Computational intelligence and bioinspired systems. Neurocomputing 70(16-18):2701-2703. https://doi.org/10.1016/j.neucom.2006.06. 009

23. Rojas I, Cabestany J, Catala A (2015) Advances in artificial neural networks and computational intelligence. Neural Process Lett 42(1):1-3. https://doi.org/10.1007/s11063-015-9419-4

24. Rojas I, Joya G, Cabestany J (2013) Advances in computational intelligence, vol 7903. Lecture notes in computer science. Springer, Berlin. https://doi.org/10.1007/978-3-642-38682-4

25. Rojas I, Joya G, Cabestany J (2015) Special issue on advances in computational intelligence and machine learning (IWANN 2013).
Soft Comput 19(9):2403-2405. https://doi.org/10.1007/s00500015-1683-8

26. Rojas I, Joya G, Catala A (2015) Advances in computational intelligence, vol 9095. Lecture notes in computer science. Springer International Publishing, Cham. https://doi.org/10.1007/ 978-3-319-19222-2

27. Rojas I, Joya G, Catala A (2015) Advances in computational intelligence, vol 9094. Lecture notes in computer science. Springer International Publishing, Cham. https://doi.org/10.1007/ 978-3-319-19258-1

28. Rojas I, Joya G, Catala A (2017) Advances in computational intelligence, vol 10306. Lecture notes in computer science. Springer International Publishing, Cham. https://doi.org/10.1007/ 978-3-319-59147-6

29. Rojas I, Joya G, Catala A (2017) Advances in computational intelligence, vol 10305. Lecture notes in computer science. Springer International Publishing, Cham. https://doi.org/10.1007/ 978-3-319-59153-7

30. Rojas I, Joya G, Gabestany J (2013) Advances in computational intelligence, vol 7902. Lecture notes in computer science. Springer, Berlin. https://doi.org/10.1007/978-3-642-38679-4

31. Sandoval F, Cabestany J, Prieto A (2011) Bio-inspired systems: computational and ambient intelligence. Neurocomputing 74(16):2591-2593. https://doi.org/10.1016/j.neucom.2011.04.005

32. Sandoval F, Prieto A, Atencia M (2017) New trends in computational intelligence. Neurocomputing 250:1-4. https://doi.org/ 10.1016/j.neucom.2016.12.068

33. Sandoval F, Prieto A, Cabestany J, Graña M (2007) Computational and ambient intelligence, vol 4507. Lecture notes in computer science. Springer, Berlin. https://doi.org/10.1007/9783-540-73007-1

Publisher's Note Springer Nature remains neutral with regard to jurisdictional claims in published maps and institutional affiliations. 